\title{
The impact of inlet channel geometry on in-cylinder swirl
}

A few chosen methods of swirl generation inside the cylinder were presented in this article. There were presented the results of impact of intake channel geometry on chosen charge movement parameters related to the air-flow inside the cylinder. Moreover, there was presented an authors own conception of flexible and steerable element applied inside the inlet channel. This element influenced on kinematics of airflow through the inlet manifold. The result of this influence was observed as a swirl inside the inlet channel and inside the cylinder. There were also presented the results of experiment related to the own conception of swirl generation. The results of experimental research were compared with results of numerical calculation of air flow prepared on basis of ANSYS CFD. As final result it was stated that proponed flexible element inside the inlet channel have a significant impact on charge kinematics and it easy can controlled by engine control unit.

Key words: intake system, swirl, ANSYS, CFD

\section{Introduction}

The modern engines are being equipped with different kinds of technical solutions related to achievement of low fuel consumption and ultra-low emission [1]. These solutions are mainly connected with the engine control system, engine mechanicals, mixture formation and combustion [2]. It is caused by an increase in engine efficiency (torque, power, specific fuel consumption, emission, etc.).

The high efficiency of energy conversion process is strongly depended on proper air-fuel mixture formation. Additionally, this mixture must be combusted in practically optimal for each engine work conditions. Thus, there is a strong need to prepare proper air-fuel mixture with the kinematics parameters (kinematics parameters of mixture?) flow related to engine's operating conditions. Among the methods which influenced kinematics of in-cylinder flow we can mention about: variable valve timing system, variable volume inlet manifold system, specially shaped geometry of intake canal, location of intake canal in relation to cylinder axis, inlet valve equipped with deflector (mainly laboratory engines), installment of additional element which is able to change flux of air flow through the inlet valve (for example by a wing throttle) and specially shaped combustion chamber (mainly direct injection engines - DI).

Currently many engines (SI and CI) are equipped with one or more of these solutions which really help to obtain more effective combustion process and decrease exhaust gas emissions - especially related to their toxic compounds.

In every expansion stroke the combustion process is patchy and unrepeatable. Thus, the measurement and controlling of kinematics of charge flow is hard to achieve at the same level. The measurement of in-cylinder flow is realized with the usage of very quick and specific measurement devices (for example - Laser Doppler Velocimeter - LDV). However, not every type of engine can be used because in most cases the view for combustion chamber is needed. Only laboratory engines equipped with specially designed optical system allows to conduct in-cylinder flow measurement. Because of this, currently mainly numerical models of combustion chambers are used for analysis of incylinder flow motion.

\section{In-cylinder flow motion}

The main type of in-cylinder flow motions are defined in literature as: tumble, squish and swirl. The chosen examples of in-cylinder flow motion were presented in Figure 1. Type of flow motion dependent on their location towards cylinder axis and scale but each represents the type of rotary motion or split rotary and forward charge motion. a)

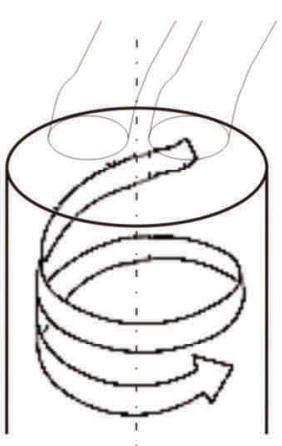

c) b)
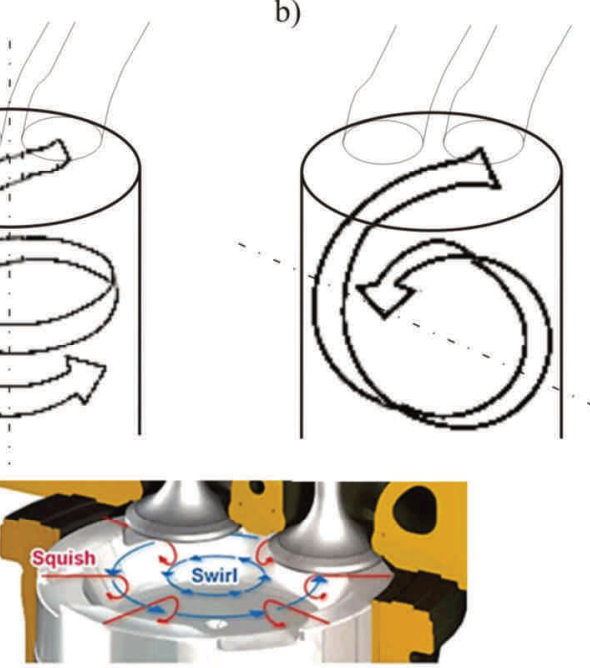

Fig. 1. Types of in-cylinder flow motion: a) swirl, b) tumble, c) squish and swirl [3]

The different type of charge motion are used for preparation of air-fuel mixture $[4,5]$ and flame propagation [68]. It is related to engine type, engine load and type of fuel (its properties). The experimental data available in literature [9-11] let us state, that currently very important for efficient fuel combustion is an achievement of swirl according to engine load [12]. Generally, swirl is defined as organized rotation of charge around the cylinder axis. Swirl is also characterized by swirl ratio (SR) and for real engine is usually defined by equation [4]: 


$$
\mathrm{SR}=\frac{\bar{\Phi}_{\mathrm{S}}}{2 \pi \mathrm{n}}[-],
$$

where: $\omega_{\mathrm{s}}-$ angular velocity of solid-body rotating flow $\left[\mathrm{s}^{-1}\right], \mathrm{n}$ - engine crankshaft rotational speed [rps].

This type of swirl ratio definition is also used during numerical research related to analysis of in-cylinder flow motion. However, the most of computer applications concerned simulation on engine charge exchange and combustion process are able to calculate many charge kinematic parameters (for example: Turbulence Kinetic Energy, Velocity, fuel drops mass distribution, etc.). One of these parameters directly characterise swirling load - Swirl Velocity. This parameter describes what is load rotation level refer to engine speed (this is Swirl Ratio).

\section{The review of methods of swirl generation}

\subsection{Swirl generated by flow}

Goto and Narusawa have been conducted research of impact of swirl on value of brake effective pressure and pressure change during combustion process [13]. The schematic view on intake channel with swirl generation system applied by them was presented in Fig. 2.

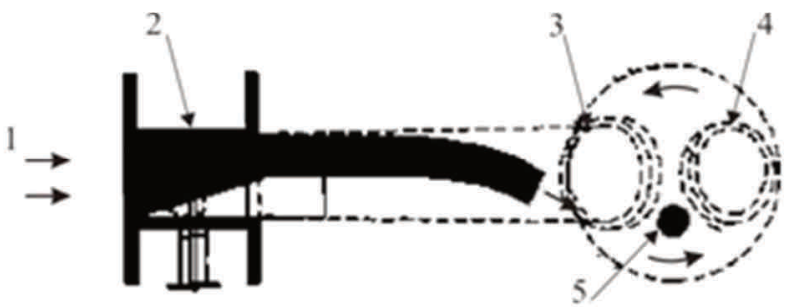

Fig. 2. The schematic view of swirl generation system [13]: 1 - direction of air-fuel mixture inlet, 2 - swirl regulation valve, 3 - inlet valve, 4 exhaust valve, 5 - spark plug

This method of swirl generation is based on change of contribution of flow flux load through intake channel and swirl generation valve (part no. 2 - Fig. 2). If the air fully flows by the inlet channel then the obtained swirl is minimalized. If contribution of flux flow through swirl valve is raising, then the swirl is maximized. Moreover, the appeared swirl inside cylinder is caused by the curvature of cylinder wall. The examples of impact of the SR on changes in mean effective pressure were presented in Fig. 3 [13].

The results of research presented in Fig. 3 indicate that the swirl ratio (SR) is significantly affected by the increase in maximal pressure. Furthermore, the pressure changes which depend on crankshaft position are more stable. These results let us state, that the swirl helps to achieve the higher value of engine operation parameters as torque and effective power with decrease of fuel consumption and toxic gases emission.

Some current engine manufacturers equip their engines (especially CI engines) with special intake system. This system is responsible for swirl generation inside the cylinder during intake stroke. The main element of this system is a wing throttle fixed near one of intake valves. The scheme of this system is presented in Fig. 4. The main disadvantage of this system is swirl generation by closing flux flow through one of inlet channels. The swirl is generated by curvature of cylinder wall connected with flow of inlet flux (no. 2 - Fig. 4).
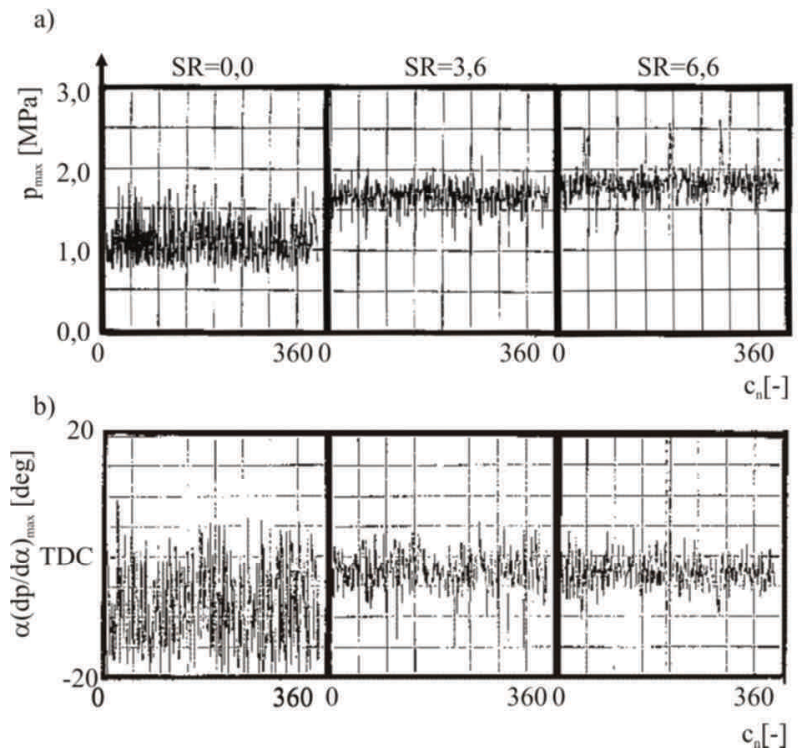

Fig. 3. The examples of impact swirl ration (SR) on [13]: a) - maximal value $\left(\mathrm{p}_{\max }\right)$ of in-cylinder pressure, $\left.b\right)$ - pressure's change $(\mathrm{dp} / \mathrm{d} \alpha)$ by engine's crankshaft position, $\alpha$ - the angle of crankshaft position, $c_{n}$ - engine cycle subsequent no., engine's operation conditions: engine speed $\mathrm{n}=1000 \mathrm{~min}^{-1}$, engine fueled by CNG and MPI system, TWO throttle wide open a)

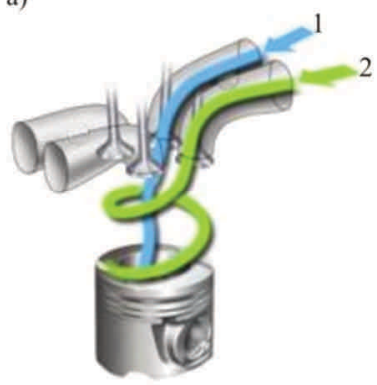

b)

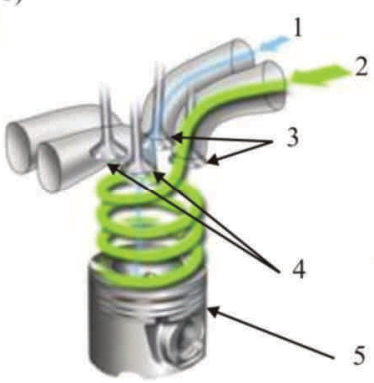

Fig. 4. The examples of swirl generation system by flow regulation [14]: a) - low swirl condition, b) - high swirl condition, 1 - flux flow by inlet canal, 2 - flux flow by inlet swirling canal, 3 - inlet valves, 4 - exhaust valves, 5 - piston

This type of swirl generation system leads to decrease in volumetric efficiency caused by a throttle wing fixed inside inlet channel. In practice, this system is used in turbocharged engines where decrease in volumetric efficiency is only partially redeemed by charging system. However, this system allows to achieve swirl parameters compatible with real time engine's load.

\subsection{Swirl generated by intake channel geometry}

The other results of research connected with assessment of impact of intake canal shape on swirl generation were presented in [10]. These research were based on swirl generation system caused by the inner wall of intake canal close to combustion chamber. The research was focused on the level of swirl (swirl ratio) and volumetric efficiency. The examples of analysed types of intake canals were presented in Fig. 5. 


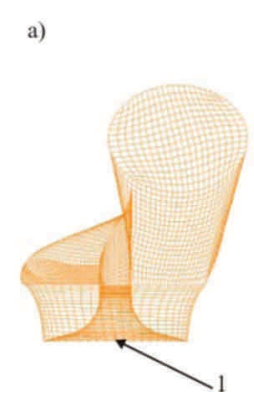

b)
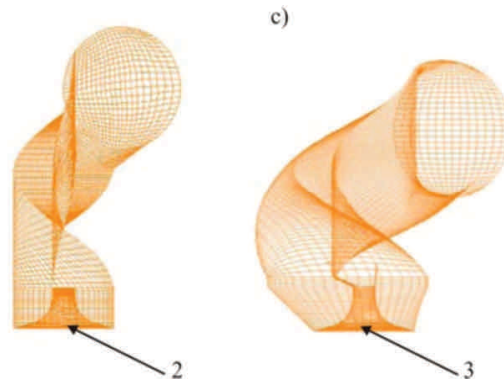

Fig. 5. The examples of discretion net of analysed type of intake channels [10]: a) - spiral type, b) - helical type, c) spirally-helical type, 1-3 localisation of inlet valve heads

For calculation of intake stroke and volumetric efficiency and swirl ratio a numerical analysis were used. As it was shown in Figure 6, the highest volumetric efficiency was achieved for helical canal. It is connected with low level of flow resistance caused by the internal wall (shape) of inlet channel. However, the highest swirl ratio was observed for spiral type on inlet channel [10].

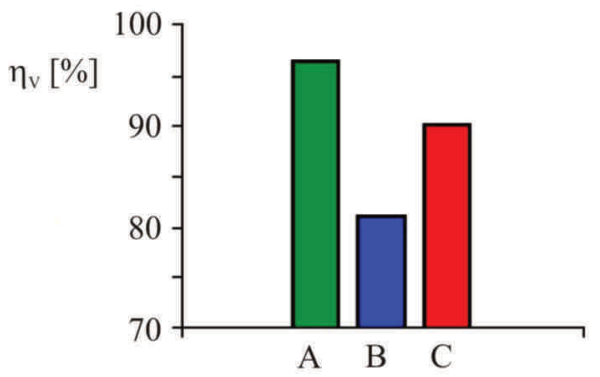

Fig. 6. The volumetric efficiency $\left(\eta_{v}\right)$ by the type of inlet channel [10]: A - helical, B - spiral, C - spirally-helical (comp. Fig. 5)

The analysis of the results of numerical simulation presented in Figure 6 and conclusions formulated in work [10] let us state that, if one wants to achieve the higher volumetric efficiency than the engine should be equipped with inlet channel of helical shape. This conclusion is not sufficient for achievement high value of engine's operation parameters like torque or power. It is connected with process of air-fuel mixture preparation. For increase in efficiency of combustion process there is a need to prepare mixture with fully vaporised fuel and fully mixed with the air for good oxygen access. Mixture formation process requires proper charge motion inside the intake channel and inside engine's cylinder. It should be obtained during: intake stroke, compression stroke and combustion.

\section{Experimental results}

\subsection{Theoretical background}

On the basis of literature analysis there was prepared the new proposition of the technical method of swirl generation. By this method it is possible to generate a different level of swirl speed inside the inlet channel and inside the cylinder. For this conception an element with flexible geometry was used. The idea of influence by flexible element on air-flow and distribution and direction of the main charge flux velocities were presented in Fig. 7.
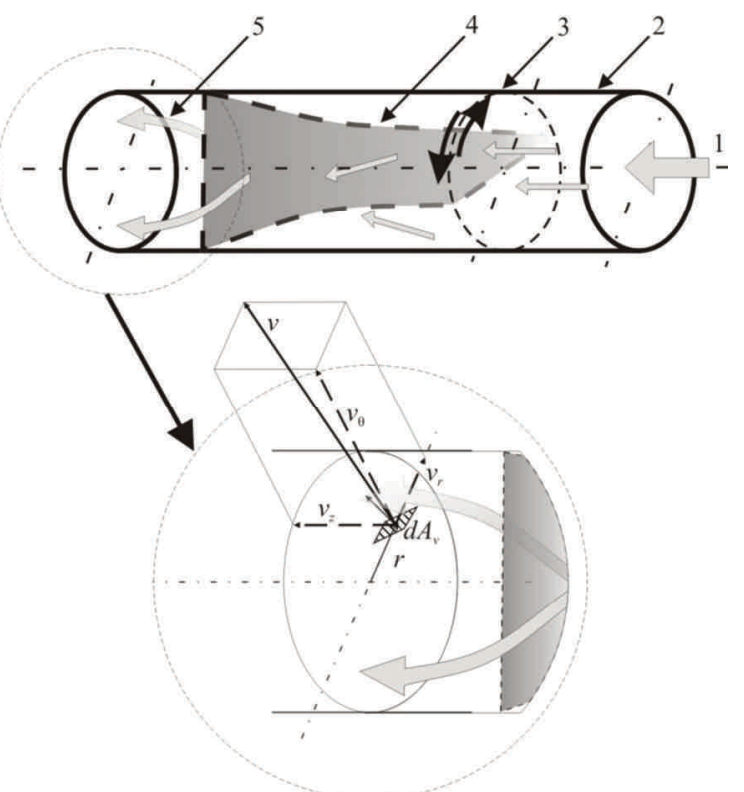

Fig. 7. Schematic of the flexible geometry element of inlet channel and velocity's distribution for each point of swirling flux $\left(\mathrm{dA}_{v}\right)$ during intake process: $r-$ inlet channel inner radius, $v_{r}-$ radial velocity, $v_{z}-$ axis velocity, $v_{0}$ - normal velocity, $v$ - mean velocity, 1 - inlet of air flux, 2 - wall, 3 - twisted the end of the flexible element (rotatable), 4 - flexible element, 5 - swirling air flux

Over flow of air-flux through the inlet channel, there is air-flow impact on the twisted shape of the flexible tape (part no. 4 - Fig. 7). It results in dividing of air-flux flow into two parts. Next twisted shape of flexible element has an impact on these two fluxes. It results in swirling of the airflow. After that the swirling charge motion is transported to cylinder through open inlet valve. The angular momentum of the air which leaves inlet channel and enters the cylinder is decreased by the friction between charge and cylinder wall. For each crank angle during induction an angular momentum of airflow decrease throughout the rest of the intake stroke and during the compression stroke due to the friction at the walls and turbulent energy dissipation within the fluid. The airflows angular momentum of the cylinder charge $\Gamma_{c}$ is changing with time according to the momentum conservation equation. It can be expressed as [13]:

$$
\frac{\mathrm{d} \Gamma_{\mathrm{c}}}{\mathrm{dt}}=\mathrm{J}_{\mathrm{i}}-\mathrm{T}_{\mathrm{f}},\left[\mathrm{kgm}^{2}\right]
$$

where: $\mathbf{J}_{\mathrm{i}}-$ is the flux of angular momentum into the cylinder, $\mathrm{T}_{\mathrm{f}}-$ is the torque due to wall friction.

The flux angular momentum for each point of intake process might be assessed as:

$$
\mathrm{J}_{\mathrm{i}}=\int_{\mathrm{A}_{\mathrm{v}}} \rho \operatorname{\rho rv}_{0} \mathrm{vdA}_{\mathrm{v}},\left[\mathrm{kgm}^{2}\right]
$$

where: $\rho$ - air density, $r$ - cylinder radius.

Friction forces due to the cylinder wall can be estimated from:

$$
\tau=0.185 \rho\left(\frac{\varpi_{\mathrm{s}} \mathrm{D}}{2}\right)^{2} \lambda\left(\operatorname{Re}_{\mathrm{D}}\right)^{-0.2}[\mathrm{~Pa}]
$$


where: $\mathrm{D}$ - cylinder bore, $\omega_{\mathrm{s}}$ - equivalent rotational velocity (swirl), $\lambda$ - empirical constant $(\lambda \approx 1.5), \operatorname{Re}_{\mathrm{D}}-$ equivalent of the flat plate Reynolds number.

Moreover, described swirl example of this phenomenon occurs with the bowl-in-piston type of combustion chamber designed for medium- and high direct-injection diesel engines. However, in spark-ignition engines spherical swirl is used to increase the burning rate, the shape of the combustion chamber which is closing to top dead centre (TDC) can also force radially inward motion of the charge.

In order to reveal the effect of flexible element of inlet channel (Fig. 7) on kinematics of air-flux flow, the new numerical model was developed. A view of numerical model is presented in Fig. 8.

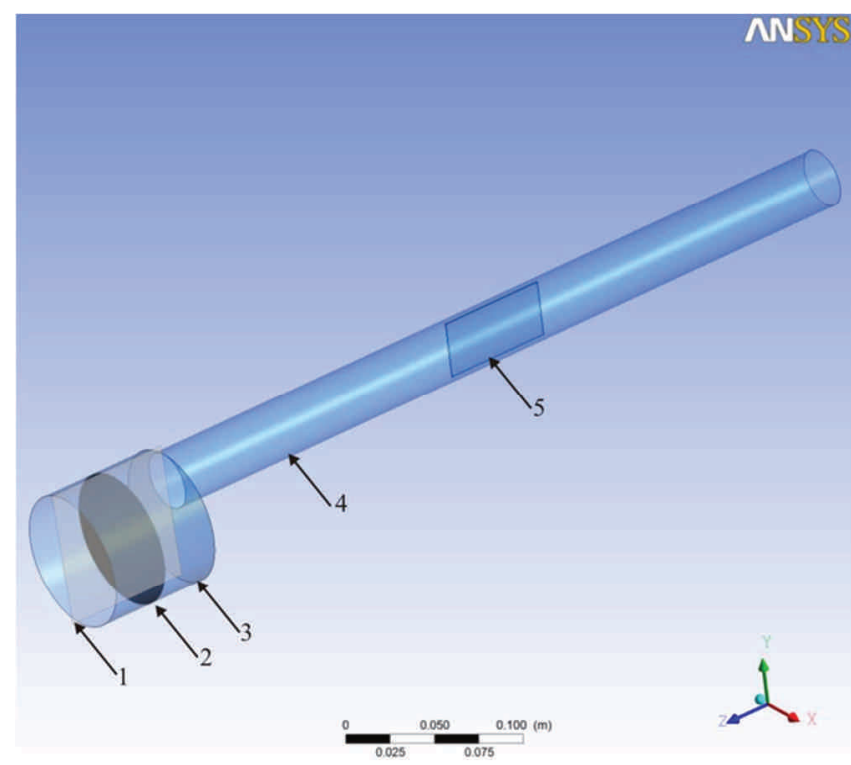

Fig. 8. Location of the planes for numerical analysis: $1-$ the cylinder axis plane, 2 - the cylinder cross-section plane, 3 - cylinder wall, 4 - inlet canal, 5 - flexible tape

The main dimensions of flow system were based on intake system of real SI engine. The characteristic dimensions of experimental stand-up were:

- inner diameter of pipe-line - $32 \mathrm{~mm}$,

- overall length $-465 \mathrm{~mm}$,

- length of flexible tape $-65 \mathrm{~mm}$,

- steel tape thickness $-0.4 \mathrm{~mm}$.

To create the geometry of the system, the commercial CFD package ANSYS Workbench was used. Used mesh was a structural mesh that was inflated near the walls. The entire mesh consists of:

- 281534 nodes,

- 16038 quad-type elements, and

- 273256 hexagonal-type elements.

Further modification (smoothing) of the mesh significantly elongated the numerical calculation without changing of obtained results. The analysed parameters were:

- swirl velocity $\left(\mathrm{S}_{\mathrm{v}}\right)$,

- Turbulent Kinetic Energy (TKE),

- airflow velocity $\left(\mathrm{V}_{\mathrm{a}}\right)$.

\subsection{Turbulence kinetic energy}

The example of the obtained numerical analysis results of the distribution of turbulence kinetic energy on the plane of the cylinder axis, which depends on the tape-twisting angle, was presented in Fig. 9. This result shows the case when the initial air flow velocity at the inlet to the flow system was $\mathrm{w}=8 \mathrm{~m} / \mathrm{s}$. a)

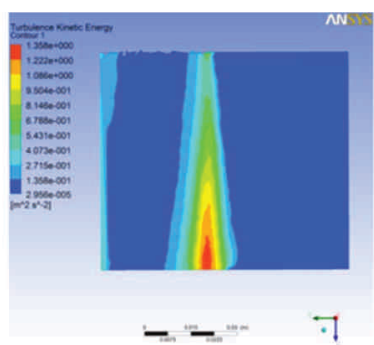

c)

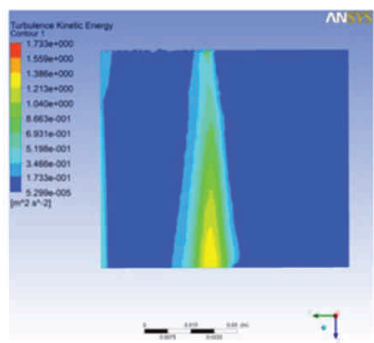

b)

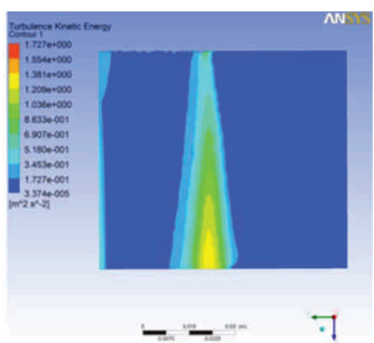

d)

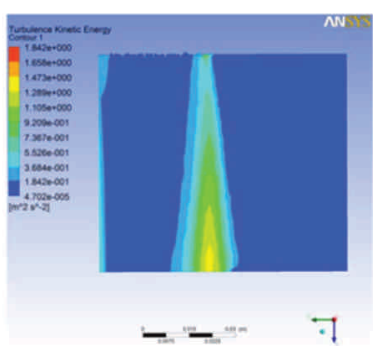

Fig. 9. The distribution of TKE inside of cylinder by the twisting angle $(\theta)$ for $\mathrm{w}=8 \mathrm{~m} / \mathrm{s}$ : a) $\theta=6 \mathrm{deg}, \mathrm{b}) \theta=12 \mathrm{deg}, \mathrm{c}) \theta=18 \mathrm{deg}, \mathrm{d}) \theta=24 \mathrm{deg}$

When the tape-twisting angle increased, the gradient of the turbulent kinetic energy decreased. Similar relations were observed for the other analysed initial air-flux flow velocities. The smaller TKE gradients confirm that the flexible element strongly affect the charge motion and their flow through the inlet system to the cylinder. In addition, the dynamic forces of molecular interaction of the swirling air flux decay the trend of the air flow to become a turbulent.

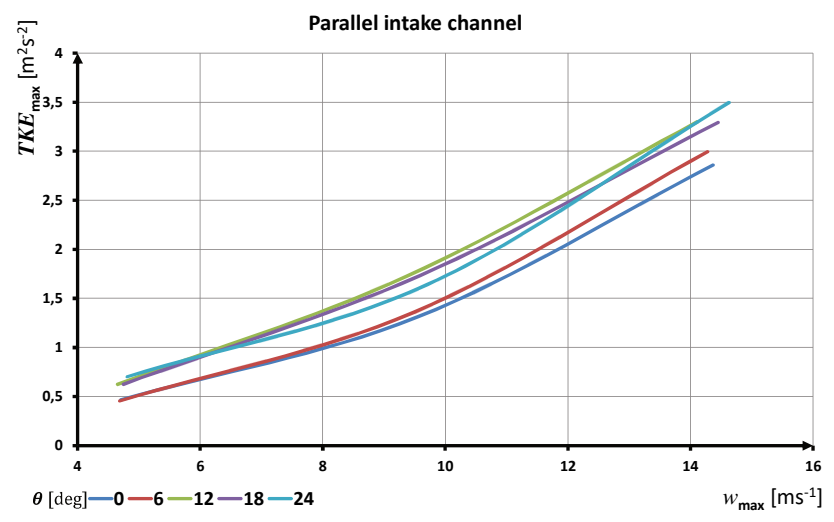

Fig. 10. The maximal turbulent kinetic energy dependence of the average air flow velocity w and an angle of twisting tape

These interactions stabilise the air flux flow. The flow stability does not help to prepare the optimal air-fuel mixture because air turbulence mixes the air and the level of fuel drops. Moreover, the airflow turbulences decrease of diameter of the fuel drops and significantly effect on a fuel vaporisation. Thus, the air turbulence should appear where the mixture forms and during combustion, but it should not cause flame dissipation. As it was shown in Fig. 10, the 
turbulent kinetic energy is related to the tape-twisting angle and the air flow velocity.

The analysis of the numerical results being shown in figure 6 let us state that the TKE is directly proportional to increases in flow velocity. Moreover, the highest turbulent kinetic energy $\mathrm{TKE}_{\max }$ was achieved when the tape-twisting angle was $\theta=12 \mathrm{deg}$. This maximal value was $20 \%$ higher than those in the other analysed examples. The more intensive tape-twisting angles do not increase turbulent kinetic energy but reduce the airflow.

\subsection{Swirl velocity}

One of the most important effects of the air flux flow through the intake channel with the flexible element is the air flux swirling. As a result, the swirl transfers to the cylinder.
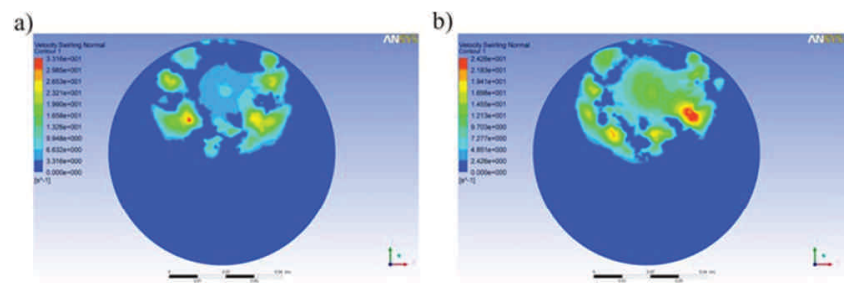

c)
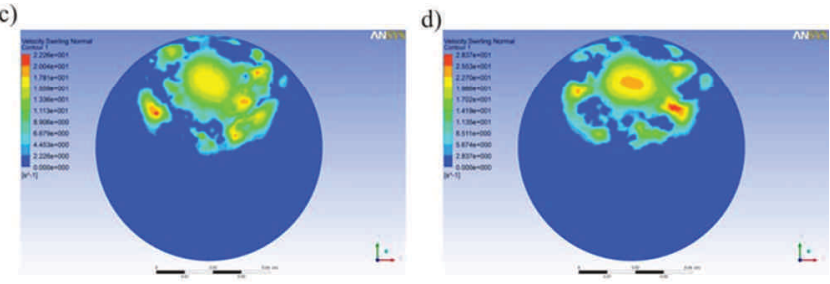

Fig. 11. The distribution of swirl inside the cylinder for charge's flow velocity $\mathrm{w}=4 \mathrm{~m} / \mathrm{s}$; a) $\theta=6 \mathrm{deg}$, b) $\theta=12 \mathrm{deg}$, c) $\theta=18 \mathrm{deg}$, d) $\theta=24$ deg

By changing the tape-twisting angle, one can control the in-cylinder charge motion. Examples of the numerical results of the swirl velocity and the tape-twisting angle were presented in Figs 11-13.

The analysis of the numerical results (Figs 11-13) of the swirl velocity showed a relation between the swirl velocity and the tape-twisting angle.
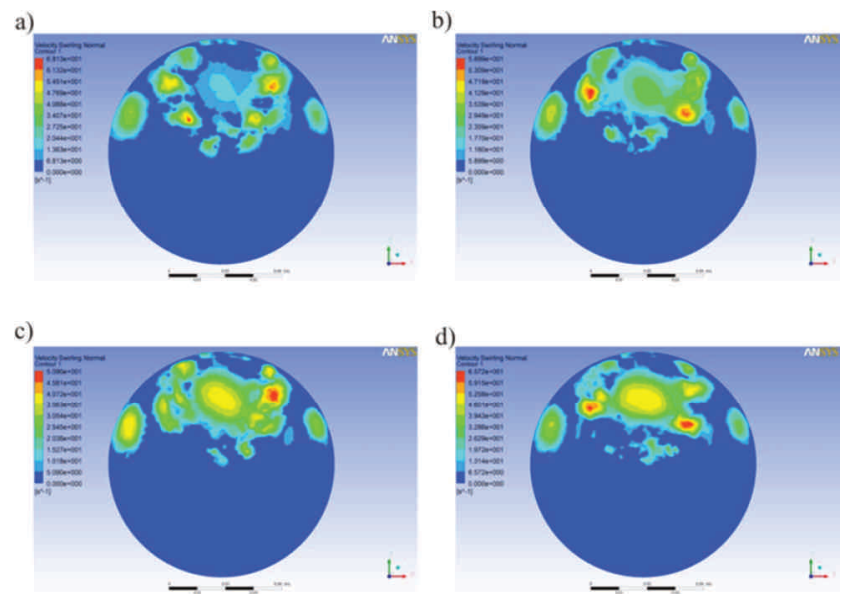

Fig. 12. The distribution of swirl inside the cylinder for charge's flow velocity $\mathrm{w}=8 \mathrm{~m} / \mathrm{s}$; a) $\theta=6 \mathrm{deg}$, b) $\theta=12 \mathrm{deg}$, c) $\theta=18 \mathrm{deg}$,

d) $\theta=24 \mathrm{deg}$
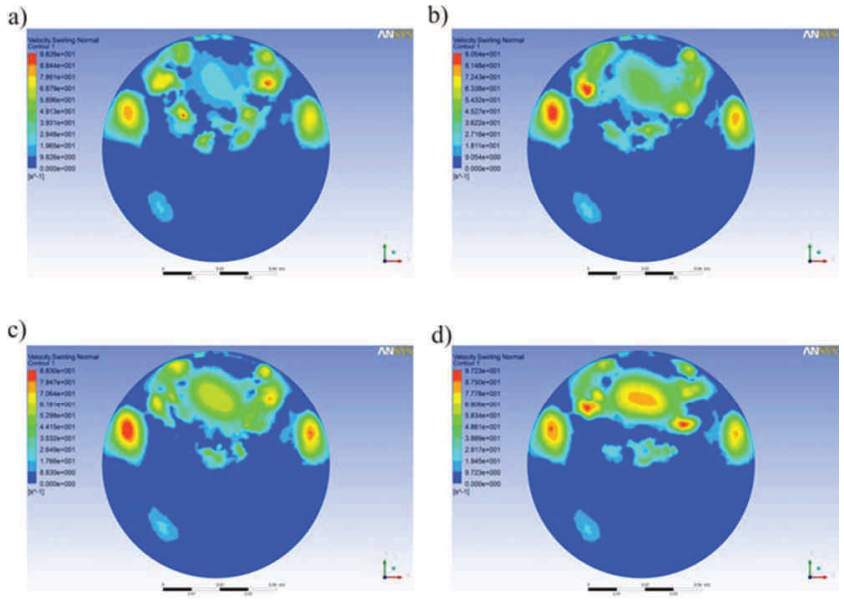

Fig. 13. The distribution of swirl inside the cylinder for charge's flow velocity $w=12 \mathrm{~m} / \mathrm{s}$; a) $\theta=6 \mathrm{deg}, \mathrm{b}$ ) $\theta=12 \mathrm{deg}$, c) $\theta=18 \mathrm{deg}$, d) $\theta=24$ deg

The surface area of the swirl air flow increases because of the tape-twisting angle, and it is also proportional to the increase of the initial air flow velocity. This relation was evaluated using the coefficient swirl area (SA), which is expressed in equation (7):

$$
\mathrm{SA}=\frac{\mathrm{A}_{\text {swirl }}}{\mathrm{A}} \cdot 100 \%,
$$

where: $A_{\text {swirl }}$ - surface area of the swirling air flux; A surface area of the cross-section of the air flow (cylinder cross-section).

By using a computer application for an analysis of the swirl area we obtained a relation among the swirl area, the initial air flow velocity (w) and the angle of flexible element twisting $(\theta)$. This relation was illustrated in Fig. 14.

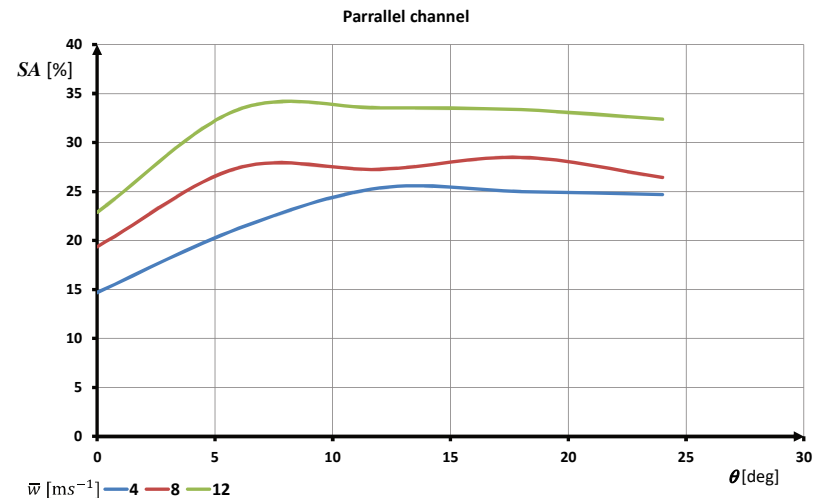

Fig. 14. The characteristic of swirl area (SA) dependence of the twisting angle $(\theta)$ and initial air flow velocity $(\mathrm{w})$ - parallel channel

The effect of the air flow velocity and the tape-twisting angle on the swirl area was observed. When the initial air flow velocity increases, the swirl area increases. The numerical analysis result shows that the tape-twisting angle significantly affects the SA, and these two quantities are directly proportional to each other. The results in Fig. 14 show that - when the initial air flow velocity was $w=4 \mathrm{~m} / \mathrm{s}$ - the SA was maximal for the angle $\theta \approx 12 \mathrm{deg}$. When the initial air flow velocity was $w=12 \mathrm{~m} / \mathrm{s}$, the maximal SA 
was achieved for the tape-twisting angle $\theta \approx 6 \mathrm{deg}$. Thus, when the initial air flow velocity increases, then the twisting angle of the flexible element decreases. Based on these analyses, one can conclude that a dynamic regulation of the tape-twisting angle is not necessary because of the relation between the kinetic energy and the twisting of the flexible element. The coefficient (SA) confirms that there is a possibility of evaluating the in-cylinder charge motion. Moreover, a proposed method of creating the swirl inside the engine cylinder using a flexible element in the intake channel allows us to control the in-cylinder charge motion.

\section{Conclusions}

Based on the numerical analysis of the flow system using the inlet system of the engine, we conclude that:

- the geometrical properties of the intake system and the geometry of the combustion chamber geometry of the piston crown significantly affect the kinematics of the in-cylinder charge motion;

_ it is possible to generate and control an in-cylinder swirl using a flexible element inside the inlet channel;

- the flexible element inside the inlet channel creates the charge swirl in the cylinder, and the obtained SA can be $50 \%$ higher than that in a standard intake system without a flexible element;

- the twisting angle of the flexible element and the initial air flow velocity significantly affect the swirl velocity and the SA value; and

- the proposed method of continuously steering the twisting angle of the flexible element helps us to fully adjust the charge kinematic parameters to actual operating conditions of engines and can easy controlled by engine control unit.

\section{Nomenclature}

CI compression ignition

CFD computed flow dynamics

CNG compressed natural gas

SI spark ignition

SA swirl area

SR swirl ratio
TDC top deat centre

TKE turbulance kinetic energy

TWO throttle wide open

w velocity (for numerical simulation)

$\theta \quad$ tape twisting angle

\section{Bibliography}

[1] MERKISZ, J., PIELECHA, J., RADZIMIRSKI, S. New trends in emission control in the European Union. Springer Tracts on Transportation and Traffic. 2014, 4.

[2] ROKOSH, U. The vehicle after treatment systems and onboard diagnosis (in Polish). WKŁ. Warszawa 2007.

[3] AMBROZIK, A. The analysis of work cycles of four-stroke piston engine (in Polish). Wyd. PŚ Kielce. 2010.

[4] HEYWOOD, J.B. Internal combustion engine fundamentals. McGraw-Hill, Singapore 1988.

[5] BENNY, P., GANESAN, V. Flow field development in a direct injection diesel engine with different manifolds. International Journal of Engineering, Science and Technology. 2010, 2(1), 80-91.

[6] KANG, K.Y., REITZ, R.D. The effect of intake valve alignment on swirl generation in a DI diesel engine. Experimental Thermal and Fluid Science. 1999, 20, 94-103.

[7] PIĄTKOWSKI, P. The chosen issues of in-cylinder charge kinematics (in Polish). Wyd. Ucz. PK. Koszalin 2013.

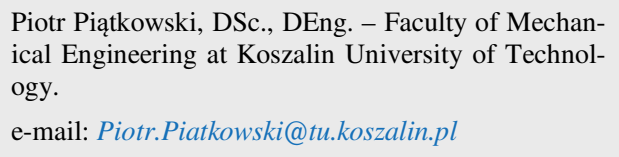

[8] PIATTKOWSKI, P. The impact of kinematics of the airflow on the efficiency of combustion process in piston engines. Combustion Engines. 2011, 2, 82-88.

[9] PIĄTKOWSKI, P. The impact of intake canal geometry on kinematics of load in combustion chamber. TEKA. 2012, 12(1), 89-94.

[10] PIĄTKOWSKI, P., BOHDAL, T. Testing of ecological properties of spark ignition engine fed with LPG mixture. Annual Set The Environment Protection. 2011, XIII, 607618.

[11] PIĄTKOWSKI, P., LEWKOWICZ, R. Motrol, 2010, 12, 115-121.

[12] MARTINS, J., TEIXEIRA, S., COENE, S. Design of an inlet track of a small I.C. engine for SWIRL. Enhancement Brazil. 2009.

[13] GOTO, Y., NARUSAWA, K. Combustion stabilization of spark ignition natural gas engine. JSAE Review. 1996, 17, 251-258.

[14] Renault technical info, 2006.

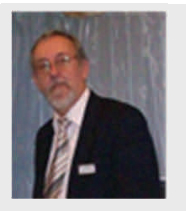

Prof. Janusz Mysłowski, DSc., DEng. - Faculty of Mechanical Engineering at Koszalin University of Technology.

e-mail: Janusz.Myslowski@plusnet.pl

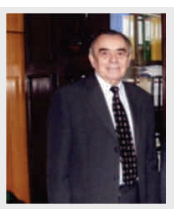

